\title{
METODOLOGIAS INTERDISCIPLINARES PARA UMA NOVA EDUCAÇÃO AMBIENTAL
}

\author{
INTERDISCIPLINARY METHODOLOGIES FOR A NEW ENVIRONMENTAL EDUCATION
}

\author{
METODOLOGÍAS INTERDISCIPLINARIAS PARA UNA NUEVA EDUCACIÓN \\ AMBIENTAL
}

\author{
Bruna Cecchin ${ }^{1}$ \\ Rafael Lopes Ferreira ${ }^{2}$
}

\begin{abstract}
Resumo
O artigo aborda a relevância das metodologias interdisciplinares para uma educação ambiental efetiva e maneiras práticas de implementá-la no âmbito não formal. Discute-se, também, a importância de alternativas educativas na educação ambiental, para uma aprendizagem mais próxima às questões atuais - que provoque um olhar mais integrador do sujeito em relação ao seu local de vivência. A pesquisa é qualitativa e de caráter bibliográfico, para melhor compreender o tema e as práticas interdisciplinares realizadas no Centro de Referência e Assistência Social (CRAS) de Muliterno/RS. Os métodos interdisciplinares são essenciais para a educação ambiental, com a finalidade de conscientizar, sensibilizar e formar sujeitos críticos. Concluiu-se que as atividades desenvolvidas contribuíram satisfatoriamente para o ensino-aprendizagem de cada sujeito envolvido. Realizou-se um Diagnóstico Situacional Participativo e cada grupo social integrante relatou suas experiências diárias; assim, foi possível estabelecer soluções práticas que aproximaram os indivíduos de seu ambiente.
\end{abstract}

Palavras-chave: Práticas socioambientais. Ensino interdisciplinar. Educação não formal. Meio ambiente.

\begin{abstract}
The article deals with the relevance of interdisciplinary methodologies for effective environmental education and practical ways of inserting it in the non-formal scope. It also discusses the importance of educational alternatives in environmental education, for a learning process closer to current issues and capable of instigating a more integrative view of the subjects concerning their place of experience. The research is qualitative and bibliographic to understand better the topic and interdisciplinary practices carried out at the Reference and Social Assistance Center (CRAS) in Muliterno / RS. The interdisciplinary methods are essential for the environmental education, for the awareness, sensitization, and critical formation of the subjects. It was concluded that the activities developed contributed satisfactorily to the teaching-learning of each subject involved. A Participatory Situational Diagnosis was carried out, and each social group reported their daily experiences; thus, it was possible to establish practical solutions that brought individuals closer to their environment.
\end{abstract}

Keywords: Socio-environmental practices. Interdisciplinary Teaching. Non-Formal Education. Environment.

\section{Resumen}

El artículo trata la relevancia de las metodologías interdisciplinarias para una educación ambiental efectiva y formas prácticas de implantarla en el ámbito no formal. Discute también sobre la importancia de alternativas educativas en la educación ambiental, para un aprendizaje más cercano a las cuestiones actuales — que genere una visión más integral del sujeto respecto a su entorno. La investigación es cualitativa y de carácter bibliográfico, para mejor comprender el tema y las prácticas interdisciplinarias realizadas en el Centro de Referencia y Asistencia Social (CRAS) de Muliterno/RS. Los métodos multidisciplinarios son esenciales para la educación ambiental, con

\footnotetext{
${ }^{1}$ Formada no Curso de Geografia. ICEG/UPF. Pós-Graduada em Educação Ambiental e Sustentabilidade na UNINTER. Acadêmica do Curso de Pós-Graduação lato sensu em Ensino de Ciências Humanas na UPF. E-mail: bruucecchin1997@gmail.com.

${ }^{2}$ Gestor Ambiental (Faculdades Integradas Camões / PR), Especialista em Biotecnologia (Pontifícia Universidade Católica do Paraná (PUC/PR), Mestre em Ciência e Tecnologia Ambiental (UTFPR), orientador de TCC do Centro Universitário Internacional UNINTER. E-mail: raffer@ alunos.utfpr.edu.br.
} 
la finalidad de crear consciencia, sensibilizar y formar sujetos críticos. Se concluye que las actividades desarrolladas contribuyeron satisfactoriamente para la enseñanza-aprendizaje de cada sujeto participante. Se realizó un Diagnóstico Situacional Participativo y cada grupo social participante hizo un relato de sus experiencias diarias; de esa manera, fue posible establecer soluciones prácticas que acercaron a los individuos a su ambiente.

Palabras-clave: Prácticas socioambientales. Educación interdisciplinaria. Educación no formal. Medioambiente.

\section{Introdução}

O presente estudo versará sobre metodologias interdisciplinares no campo da Educação Ambiental (EA). É imprescindível a discussão de questões ambientais na contemporaneidade, tanto nas esferas formais, informais e não formais, como ressalta o autor:

A questão ambiental tem se tornado uma pauta constante nos diversos segmentos da sociedade - nos governos, nas organizações civis e, sobretudo, entre as pessoas que buscam cada vez mais se informar sobre o futuro mundial no que concerne aos recursos naturais (SILVA; PRZBYSZ, 2014, p. 16).

A educação ambiental tem objetivos claros e pertinentes para a atualidade, pois vivemos em uma sociedade que tem uma relação com o meio ambiente e tudo que o compõe principalmente ao extrair seus recursos naturais para fins lucrativos. Nesse contexto, é fundamental trabalhar novas formas de condutas e valores na sociedade. No que concerne à EA, existe uma preocupação em estudar temas locais e globais que são emergentes; para tal, é preciso novas visões de mundo, como descreve o autor:

[...] entendo que é pelo processo de transformações sociais, na construção de uma nova visão de mundo, de uma nova racionalidade e seus paradigmas, que se possibilita a realização de novos indivíduos em uma nova sociedade, em um movimento recíproco (dialético de transformação simultânea indivíduo e sociedade), capaz de estabelecer uma nova relação entre sociedade e natureza e, reciprocamente, entre seres humanos e natureza (GUIMARÃES, 2020, p. 42).

Com as práticas sociais e econômicas descomprometidas e despreocupadas perante as questões ambientais, é imprescindível que os educadores elaborem e versem dinâmicas e atividades que reintegrem o ser humano com o meio ambiente. A educação ambiental apresenta uma proposta que contribui para um desenvolvimento mais sustentável da sociedade, sem prejudicar gradativamente o meio natural.

Diante dessa perspectiva, é indispensável que haja, no contexto da educação ambiental, um conhecimento que não seja isolado e fragmentado, ao destacar que tudo que está disposto no espaço é interligado de alguma forma; com isso, existem inúmeras interações entre os seres (bióticos e abióticos) e o ambiente. 
O ser humano, por exemplo, estabelece vínculos e desenvolve práticas no seu espaço de vivência, tendo contado direto com o meio ambiente e tudo que o abrange, construindo e produzindo. Tais relações devem ser repensadas e debatidas, pois as ações antrópicas em suas dimensões causam inúmeros impactos ao meio.

Destarte, são necessárias mudanças de paradigmas e a desestruturação da forma de ensino tradicional, que em suma é disciplinar e faz com que o indivíduo se distancie da realidade como um todo. $\mathrm{O}$ ensino interdisciplinar é recorrentemente discutido e em alguns âmbitos, principalmente o formal, é utilizado para desempenhar práticas educativas.

Os mediadores do conhecimento devem pensar em novas propostas de ensino, com o desenvolvimento de técnicas, procedimentos e métodos que abarquem as mudanças que, frequentemente, acontecem no espaço, sempre considerando seus principais sujeitos. Como destaca o autor:

Exercitar uma forma interdisciplinar de teorizar e praticar educação demanda, antes de mais nada, o exercício de uma atitude ambígua. Tão habituados nos encontramos à ordem formal convencionalmente estabelecida, que nos incomodamos ao sermos desafiados a pensar com base na desordem ou em novas ordens que direcionam ordenações provisórias e novas (FAZENDA, 2015, p. 13).

O comprometimento da interdisciplinaridade é mudar a estrutura e configuração fragmentada que cerca a educação há muito tempo, e que já não dá o suporte necessário para o novo contexto global. É relevante que se amplie os horizontes para algo inovador, que abranja a dinamicidade que a educação ambiental envolve e a intrínseca relação do sujeito e seu espaço de vivência.

Neste contexto, a interdisciplinaridade compreende uma visão dilatada para o conhecimento e a aprendizagem do sujeito, ressaltando sua identidade e suas interpretações. Portanto, a educação ambiental busca ir além, desfocando da transmissão decorada das informações. No momento, faz-se necessário que o educador ambiental desperte a reflexão, compreensão e sensibilização de seus educandos e sociedade em geral, a partir de ações participativas. Como ressalta o autor:

Mudar pessoas significa fazer com que elas mesmas assumam esse papel, reflitam mais sobre seus valores e procurem compreender o que está por trás de cada ação humana. Uma ação irrefletida, dizia Milton Santos, outro pensador brasileiro, é uma ação débil, uma ação de dominação. Por outro lado, uma ação refletida é uma manifestação da vontade de que esse mundo melhore, porque o compreendemos e sabemos em qual direção queremos que ele vá (DOURADO; BELIZÁRIO, 2012, p. 19). 
O trabalho tem por objetivo apresentar novas alternativas interdisciplinares no que tange à educação ambiental em esfera não formal. Provoca-se e instiga-se um olhar mais crítico do sujeito em relação ao seu local de vivência e ao mundo que o cerca, fazendo com que construa novos enfoques direcionados à educação ambiental.

Os métodos que serão traçados para se alcançar os objetivos são de extrema importância; para tal, a pesquisa é qualitativa e se alicerçará em estudos teóricos e práticos (estudo de campo). Os estudos teóricos um embasamento o tema em pauta, enquanto as práticas darão mais ênfase à relevância de atividades interdisciplinares, focadas na realidade dos sujeitos participantes. O procedimento ocorrerá através da abordagem teórica, desenvolvido uma abordagem teórica sobre o tema; em seguida, um diagnóstico local será realizado, a partir de oficinas e conversas participativas. Para conclusão das práticas, serão debatidas e realizadas ações que comprometam e estreitem as relações de cada integrante — principalmente, com a natureza.

\section{Aplicabilidades metodológicas em relação à interdisciplinaridade no contexto não formal}

A interdisciplinaridade tem por princípio fomentar novas compreensões de mundo e toda a sua complexidade, o que envolve desde aspectos sociais, políticos, culturais e ambientais. As diversas disciplinas do conhecimento podem se confrontar e interagir sobre óticas de diferentes temas; com isso, abre-se uma infinidade de possibilidades de trocas de conhecimentos - o que não acontece quando cada disciplina é trabalhada isoladamente.

Para tanto, é necessário que os educadores repensem suas metodologias, didáticas e se adequem a novas possibilidades para suas mediações e para uma observação mais aproximada dos fenômenos. A interdisciplinaridade tem o intuito de estabelecer novas propostas que se contrapõem aos métodos disciplinares, ainda tão trabalhados na educação. Como o autor destaca:

\footnotetext{
A superação dessa limitação vem sendo anunciada desde os anos 60 pela interdisciplinaridade, cuja proposição permite não apenas a observação do fenômeno por uma lente grande-angular como permite através da mobilidade que a sustenta aproximações ou distanciamentos do fenômeno observado, conforme o estudo assim o requerer. Poder observar sob variadas óticas vai despertando no investigador o gosto pela dúvida, pela pesquisa, incitando-o a percorrer novos caminhos teóricos para explicitação do real (FAZENDA, 2016, p. 63).
}

A educação ambiental abrange diversos pilares do conhecimento e não trabalha somente com os recursos naturais, mas também com a política, a cultura, a sociedade, ou seja, diversas 
extensões. A base da EA é propriamente a educação, preparando cada indivíduo para refletir na ótica de suas realidades. De acordo com Philippi Jr \& Pelicioni (2014), a educação ambiental forma e prepara cidadãos para a reflexão crítica e para uma ação social corretiva, ou transformadora do sistema, de forma a tornar viável o desenvolvimento integral dos seres humanos.

A reestruturação dos temas é fundamental para que a interdisciplinaridade aconteça efetivamente, com enriquecimento recíproco entre os agentes sociais envolvidos. É imprescindível que nos âmbitos não formais existam práticas que compreendam as diferentes interligações que regem e permitem o equilíbrio ecológico.

A educação ambiental, no propósito de desenvolver a interdisciplinaridade, visa com que os indivíduos repensem suas atitudes, tanto localmente quanto globalmente, desenvolvendo no sujeito novas aprendizagens, sensibilizações, conhecimentos, valores, competências, habilidades e um novo olhar, mais crítico e aguçado. A partir das concepções da autora:

As sugestões de trabalho procuram conscientizar os alunos (e os professores) da responsabilidade de cada indivíduo na conservação do meio em que vive. Se não nos conscientizarmos de nossas responsabilidades pessoais, se não percebermos nossa contribuição para o estado atual de nosso planeta, não vai haver ação significativa a favor do meio ambiente! (CURRIE, 2016, p. 13).

Além das atividades individuais, é essencial, também, trabalhar coletivamente, propondo que analisem e interpretem o seu local de vivência para que, posteriormente, possam fazer um apanhado geral. Este trabalho objetiva contribuir na formação cultural da população, com uma visão voltada para a preservação e conservação do meio ambiente, considerando, também, as futuras gerações. Assim, segundo o autor:

\footnotetext{
É impossível mudar a realidade sem conhece-la objetivamente. Dessa forma, o desenvolvimento de um processo de educação ambiental implica que se realize, logo de início, um diagnóstico situacional, a partir do qual deverão ser estabelecidos os objetivos educativos a serem alcançados (PHILIPPI; PELICIONI, 2014, p. 4).
}

Logo, é fundamental que o educador ambiental trace metas e objetivos, iniciando com um diagnóstico situacional. Destarte, é relevante escolher procedimentos adequados para se trabalhar a EA em determinado grupo social, visualizando suas necessidades e os diferentes contextos que se encontram, para que possam dar maior ênfase ao que acontece em sua esfera socioambiental. 


\section{Metodologia}

Com o objetivo de contribuir para a maior abrangência e dinamicidade do ensinoaprendizagem em educação ambiental, realizaram-se pesquisas bibliográficas e práticas, para que todos os objetivos traçados fossem alcançados satisfatoriamente.

É necessário destacar a relevância que os processos metodológicos tiveram para a pesquisa, sendo que foi possível interligar a teoria com a prática (práxis) e desenvolver inúmeras atividades no contexto da EA. As bibliografias auxiliaram para uma maior compreensão do tema tratado e explanação dos eixos norteadores.

A parte prática (de campo) da investigação foi preponderante para a análise e efetivação do que foi estudado. Pretende-se que as atividades de campo incentivem os profissionais, das áreas formal, não formal e informal, a construírem práticas instigantes; dessa forma, o indivíduo pode refletir sobre seu contexto social e ambiental.

Primeiramente, buscaram-se referenciais teóricos relevantes para a pesquisa, como autores que versam sobre a Educação Ambiental e Interdisciplinaridade. Em seguida, com as técnicas da assistência social e o auxílio da orientadora social do CRAS (Centro de Referência e Assistência Social) do munícipio de Muliterno-RS, discutiram-se as principais problemáticas socioambientais encontradas no espaço rural e urbano. Analisar as problemáticas é fulcral para buscar soluções apropriadas e alcançar os objetivos.

Nesta perspectiva, foram estabelecidas práticas que serão explicadas nos próximos capítulos; elas foram desenvolvidas com os grupos de Serviço de Proteção e Atendimento Integral à Família (PAIF) e dos Serviços de Convivência e Fortalecimento de Vínculos (SCFV) — serviços ofertados pelo CRAS.

\section{Resultados das práticas interdisciplinares no centro de referência e assistência social}

Para a aplicação das atividades interdisciplinares em EA, definiu-se como público-alvo os grupos participantes do Centro de Referência e Assistência Social de Muliterno/RS. As atividades práticas efetuadas no centro ocorreram em fevereiro e março de 2020.

Para o desenvolvimento metodológico de cada atividade, houve a participação da equipe que tem maior contato com os usuários: a assistente social, a psicóloga, a orientadora social e a educadora ambiental (autora). A experiência apresentou resultados satisfatórios, pois cada atividade foi elaborada de forma interdisciplinar, unindo diferentes áreas do conhecimento.

A interdisciplinaridade contribuiu para que vários eixos fossem considerados, como os contextos social, emocional, ambiental e pedagógico. Estes diferentes aportes contribuíram para 
que as atividades fossem integradoras e apresentassem conhecimentos oriundos de diferentes visões e seguimentos.

\subsection{Atividades interdisciplinares com os usuários do SCFV}

\subsubsection{Expedição Investigativa}

Com os usuários do SCFV, no primeiro encontro dos dias 02 e 03 de março/20, foi realizada uma expedição investigativa. Para tanto, desenvolveu-se uma atividade de campo pelo espaço urbano de Muliterno, para observar como a população se portava em relação à disposição de seus resíduos sólidos. Durante a prática, os sujeitos fizeram uma análise mais aproximada da realidade, visualizando na prática conceitos previamente discutidos, aguçando suas curiosidades e questionamentos; assim, foi possível esclarecer dúvidas e estimular suas próprias concepções durante a trajetória.

Posteriormente, tanto os adolescentes quanto as crianças desenvolveram, de formas diferenciadas, a resolução da seguinte problemática: Quais são as principais causas do acúmulo de resíduos sólidos no espaço urbano de Muliterno/RS?

Com os adolescentes, a resolução da problemática foi a partir de discussões em grupo; cada um apontou as causas e possíveis soluções. Entre as respostas de cada grupo, constatouse que algumas das causas são: o desinteresse, despreocupação e desrespeito da sociedade perante a destinação de seus resíduos, separação incorreta dos resíduos, problemas de acúmulos de resíduos nos rios do município e morte de animais por ingerirem resíduos ou água contaminada.

Como soluções importantes para mudanças no contexto atual, destacaram a necessidade de mais lixeiras na praça da cidade, mecanismos (como, por exemplo, placas de conscientização) que conscientizem os cidadãos a serem mais responsáveis com o meio ambiente, coleta seletiva também nos domingos e maior reutilização dos resíduos.

Após o trabalho de campo, as crianças foram reunidas em grupos; cada grupo fez um cartaz com desenhos (Figura 1) que representavam tudo que observaram durante a trajetória; demonstrou-se, assim, a criatividade delas e a realidade encontrada em suas comunidades. 


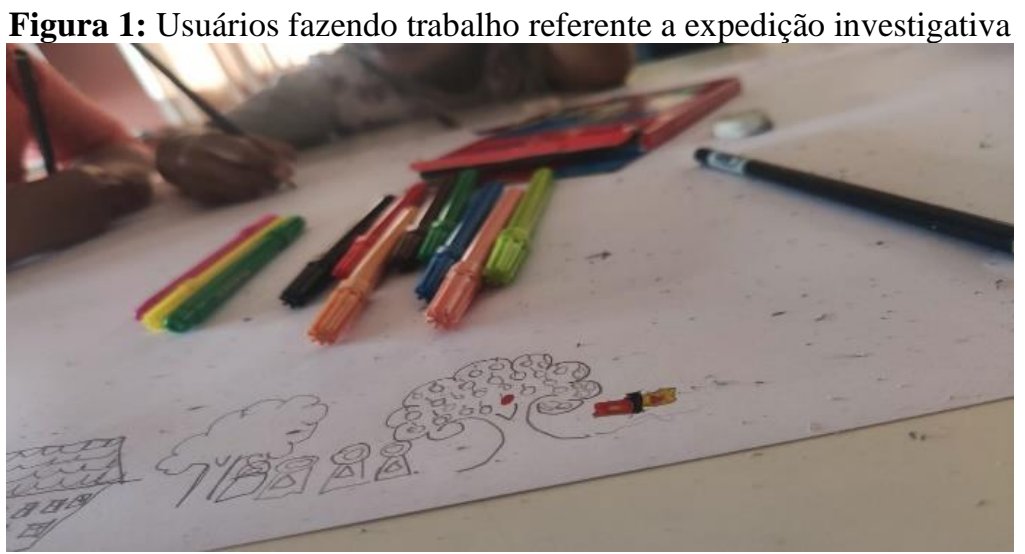

Fonte: a autora (2020)

As respostas para as causas e soluções foram produtivas; cada grupo conseguiu discutir acerca de tudo que visualizaram durante a expedição investigativa, e surgiam soluções até mesmo imprevistas. Entre elas, destacaram-se duas principais: a prisão por todos os "males" que causou e fazer o indivíduo recolher todos os resíduos das ruas da cidade. A atividade fez com que conseguissem se expressar de forma mais crítica, a partir de suas aprendizagens.

\subsubsection{Detetives Ambientais}

Nos dias 09 e 10 de março/20, realizou-se uma dinâmica chamada "Detetives Ambientais", com as turmas dos adolescentes e das crianças. Para a dinâmica acontecer, ocuparam-se três salas, cada qual com uma charada para completarem. Além da charada, em cada uma das salas havia uma problemática expositiva e que deviam também solucionar.

$\mathrm{Na}$ primeira sala, havia vários tipos de resíduos espalhados por toda a sala (Figura 2) e, também, três tipos de lixeiras: resíduos recicláveis, resíduos orgânicos e rejeitos. Além dos usuários completarem a charada "Ao descartar um resíduo devo: ”, eles precisaram colocar cada resíduo em sua lixeira correspondente. 
Figura 2: Primeira sala demonstrativa para os detetives ambientais

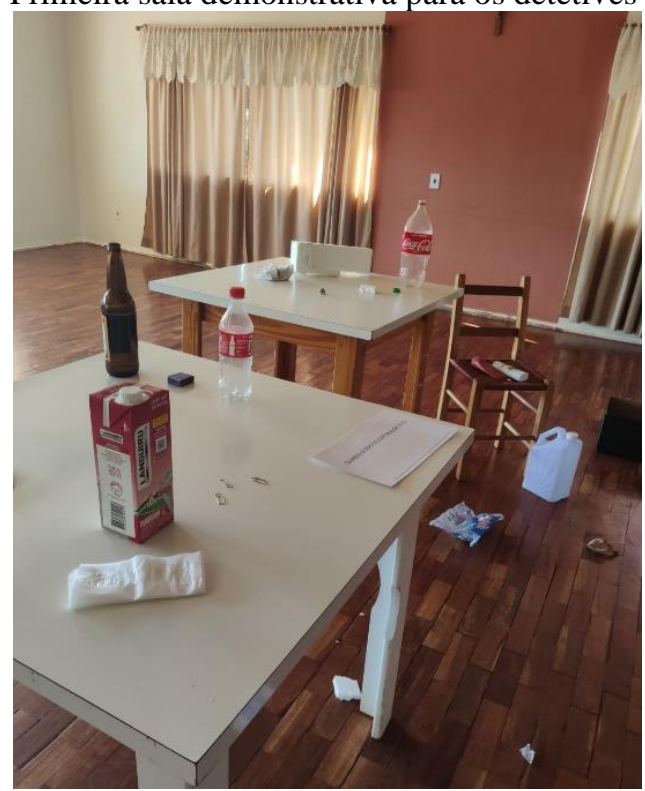

Fonte: a autora (2020)

Cada um dos grupos recebeu, antes de iniciar a atividade (Figura 3), uma luva e uma lupa customizada com EVA, para que pudessem interpretar os personagens "Detetives Ambientais". Observou-se um grande envolvimento dos usuários na atividade, todos empenhados em solucionar as problemáticas. Foi possível instigá-los a perceber questões simples e importantes do nosso cotidiano, como esse exemplo de recolher os resíduos e colocálos em suas lixeiras correspondentes.

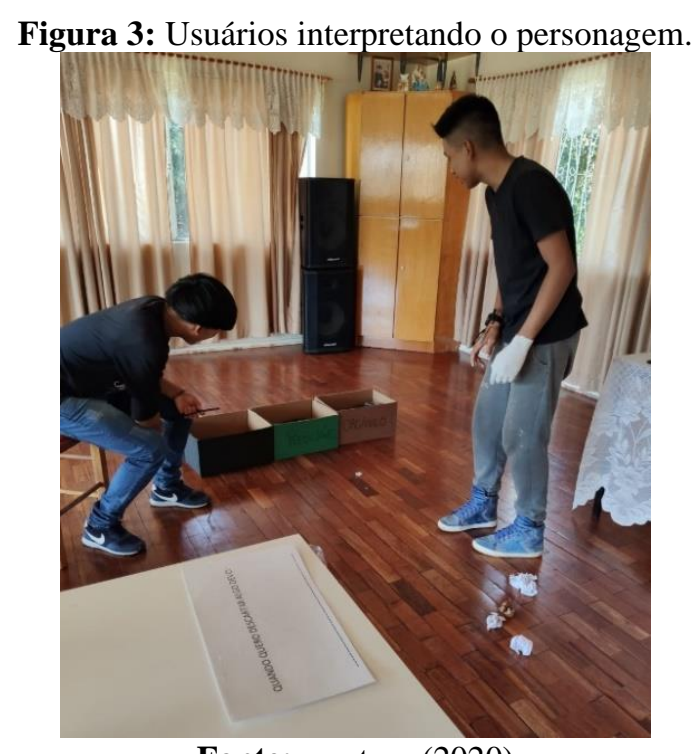

Fonte: a autora (2020)

Na segunda sala, deixou-se a charada "Ao sair de ambiente devo:”. Os participantes deveriam, além de achar a frase/imagem que completava a charada, perceber que as luzes 
estavam todas ligadas e que o dever deles era desligá-las. Neste momento, eles perceberam que os pequenos atos podem fazer a diferença, pois, observou-se que muitos grupos ficaram na dúvida do que poderia estar incorreto na sala, mas ao achar a frase obtinham a resposta. A percepção das pessoas em relação ao meio ambiente e uso dos recursos naturais, por vezes, se restringe a poucas questões; nota-se que não há um entendimento integrado da interdependência dos recursos naturais e ações humanas, desassociando-os.

$\mathrm{Na}$ terceira fase desta atividade, eles precisavam desvendar a charada "Quando termino de ocupar a água devo:”. Neste momento, eles deveriam entrar em dois banheiros; ao entrar, havia as torneiras abertas, desperdiçando água, e alguns papéis estavam dispostos no chão (Figura 4). Os participantes deveriam fechar as torneiras, recolher os papéis e achar a frase/imagem para completar a charada.

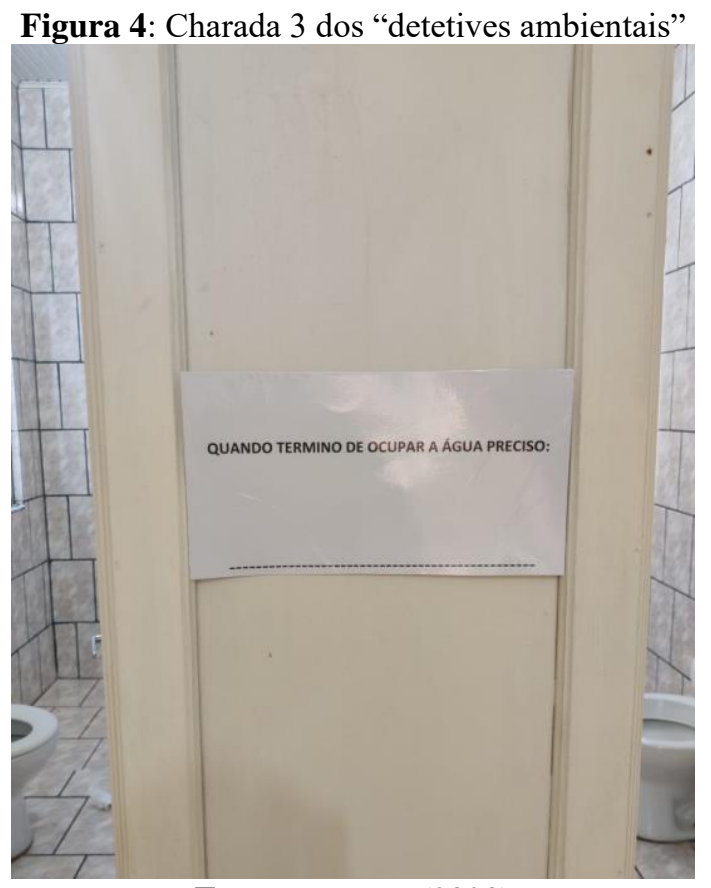

Fonte: a autora (2020)

No término do circuito, das três fases, cada grupo se deparava no final com uma carta deixada pelo "ser humano imaginável" que fez todas as atrocidades ao percorrer as salas. Nesta carta, ele parabenizava os participantes por terem chegado até o final e dizia que, agora, deveriam encontrá-lo e dar-lhe a punição que achassem prudente, por todas as suas agressões ao meio ambiente.

Neste momento, cada grupo foi à procura da imagem; ao encontrá-la, pensavam nas punições. Entre as punições, os grupos citaram a possibilidade de prisão e a responsabilidade de recolher todos os resíduos encontrados nas ruas da cidade. 
O objetivo da atividade era de forma criativa, dinâmica e lúdica, envolver os usuários e, nessa mesma conjuntura, fazer com que percebessem atitudes que muitos têm em seu dia a dia, que podem ser mudadas e melhoradas. Satisfatoriamente, o objetivo foi alcançado e pode-se observar mudanças significativas nas atitudes e alguns hábitos nos usuários participantes.

\subsubsection{Placas de conscientização}

O propósito de produzir com os adolescentes e crianças placas de conscientização é desenvolver uma iniciativa coletiva e socioambiental de forma criativa e sensibilizadora, para demonstrar à sociedade local novas propostas. As mensagens e palavras-chave escolhidas pelos usuários servem, também, para chamar a atenção da sociedade para abordagens fundadas nas questões socioambientais.

Foram organizados grupos com os usuários e cada integrante era responsável de valerse de sua criatividade para desenvolver as placas; alguns utilizaram, também, as redes sociais para obter mais ideias. O trabalho foi satisfatório, pois, cada grupo se inspirou e pensou em frases e formas que despertassem o interesse posterior dos leitores (munícipes de Muliterno e visitantes).

Concluiu-se que as diversas abordagens e a criatividade estimularam os usuários a se comprometerem durante toda a atividade; com isso, representaram as perspectivas e preocupações que os norteiam. A Figura 5 apresenta algumas das placas que foram desenvolvidas. 
Figura 5: Placas desenvolvidas pelos usuários

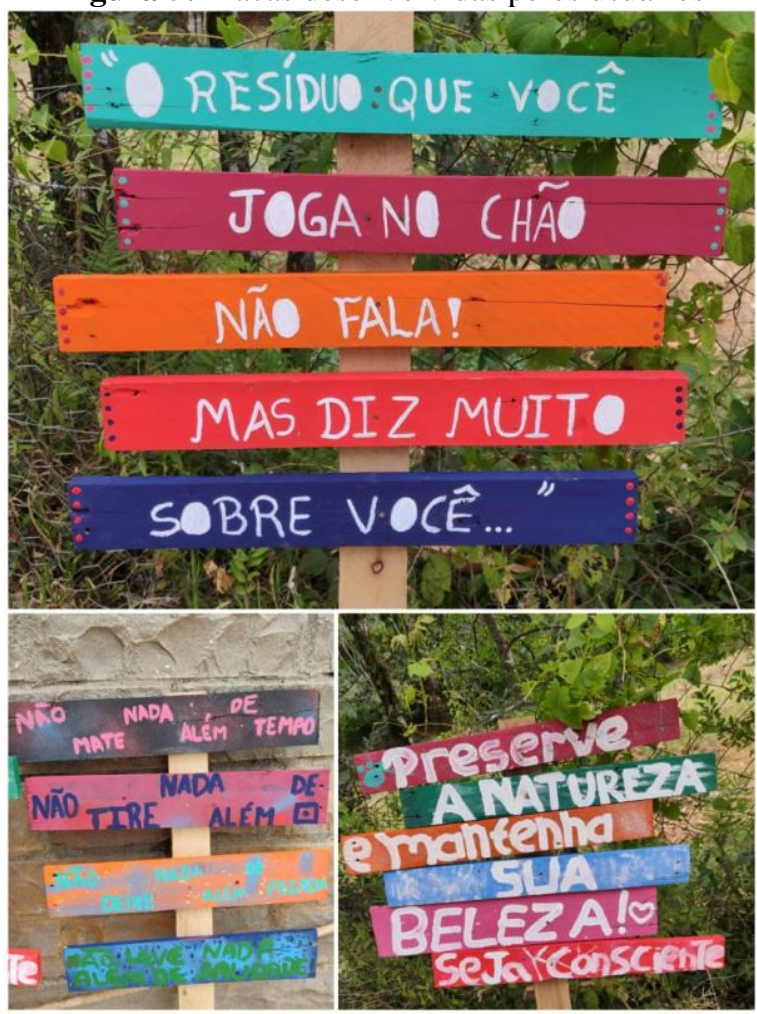

Fonte: a autora (2020)

\subsection{Atividades interdisciplinares com os grupos do PAIF}

\subsubsection{Conversa Participativa}

O PAIF é um dos serviços ofertados pelo CRAS de Muliterno/RS, o qual versa a partir do Ministério do Desenvolvimento Social e Combate à Fome:

O Serviço de Proteção e Atendimento Integral à Famílias - PAIF consiste no trabalho social com famílias, de caráter continuado, com a finalidade de fortalecer a função protetiva das famílias, prevenir a ruptura dos seus vínculos, promover seu acesso e usufruto de direitos e contribuir na melhoria de sua qualidade de vida [...] (BRASIL, 2013, p. 10)

Inicialmente, para haver uma compreensão do conceito e objetivo da Educação Ambiental, realizou-se uma conversa com as mulheres que participam do grupo do PAIF. São dois grupos predominantes, um de mulheres que residem no espaço urbano e o outro de mulheres que residem na reserva indígena.

No decorrer da conversa, foram abordados aspectos como: a relação entre o ser humano e o meio ambiente, objetivos da EA, problemas ambientais locais que afetam globalmente e as marcas que desejamos deixar, tanto socialmente quanto ambientalmente no mundo. 
O primeiro grupo do PAIF, em que foi realizada a conversa participativa, aconteceu no dia 13 de fevereiro/20. Observou-se a gratificante troca de conhecimentos, pois, cada sujeito trouxe nas suas falas os fatos de seus cotidianos que consideram relevantes. Para a conclusão da conversa, foram feitos grupos e cada um deveria escrever em um rascunho de papel problemas-situações ambientais que consideravam pertinentes no município.

As situações-problema mais ressaltadas foram: os resíduos encontrados nas ruas e nos rios, o mau cheiro advindo da disposição incorreta de resíduos em curso d'água e a falta de colaboração com a limpeza. Em seguida, um cartaz foi elaborado com as respostas, para serem visualizadas e discutidas no grupo geral.

No dia 28 de fevereiro/20, efetuou-se a conversa com o segundo grupo do PAIF, representado pelas mulheres indígenas. Neste grupo, também foi possível averiguar os conhecimentos referentes ao tema exposto. As problemáticas colocadas em pauta foram, em contrapartida, com o outro grupo, destacadas anteriormente. As problemáticas expostas foram: descarte incorreto de resíduos, poluição dos rios, saneamento básico, falta de água, desmatamento, poluição do ar, queimadas, poluições advindas dos agrotóxicos e seu descarte incorreto.

Para o fechamento da conversa, no encadeamento das respostas, foi desenvolvido um cartaz para verificar quais problemas mais se sobressaíram e as diferentes visões de cada grupo.

Com a finalização da atividade, com os dois grupos, foram averiguadas as respostas e discussões; a partir delas, pode-se pensar em ações efetivas e que constituíssem a possibilidade de novas propostas, ao considerar a situação-problema que fosse mais pertinente ao grupo social.

Portanto, constataram-se as visões dos grupos em relação aos seus espaços de vivência, onde constantemente fazem trocas de relações, não somente ambientais, mas sociais, culturais e políticas. É fulcral ressaltar que o ambiente onde é realizada uma conversa ou discussão deve ser amistoso e aconchegante, para que não haja receios ao se abordar fatos de sua realidade e distintas compreensões.

\subsubsection{Práticas coletivas}

Discutiram-se, com as técnicas da assistência social, ações que poderiam ser realizadas com os grupos e que fossem de encontro com as problemáticas destacadas no primeiro encontro. A ação desenvolvida é relacionada com a preocupação do descarte incorreto dos resíduos, 
principalmente os domésticos. Deste modo, a ação pensada foi uma conversa informativa, com ênfase na separação correta e uma solução prática para os resíduos orgânicos.

Com o grupo residente do espaço urbano, promoveu-se uma demonstração de como separar os resíduos e a exemplificação, de forma fácil e acessível, de composteiras que podem ser desenvolvidas nas próprias residências dos participantes. Uma composteira é uma forma prática de utilizar os resíduos orgânicos domésticos, transformando-os em um composto orgânico, que, posteriormente, pode ser aproveitado na adubagem do solo.

Dois materiais (Figura 6) foram apresentados ao grupo para a realização da composteira (em baldes e galões) e, em seguida, as etapas para a sua produção foram ilustradas. Essa técnica é muito viável e pode-se aproveitar, até mesmo, o chorume, como um biofertilizante para as plantas.

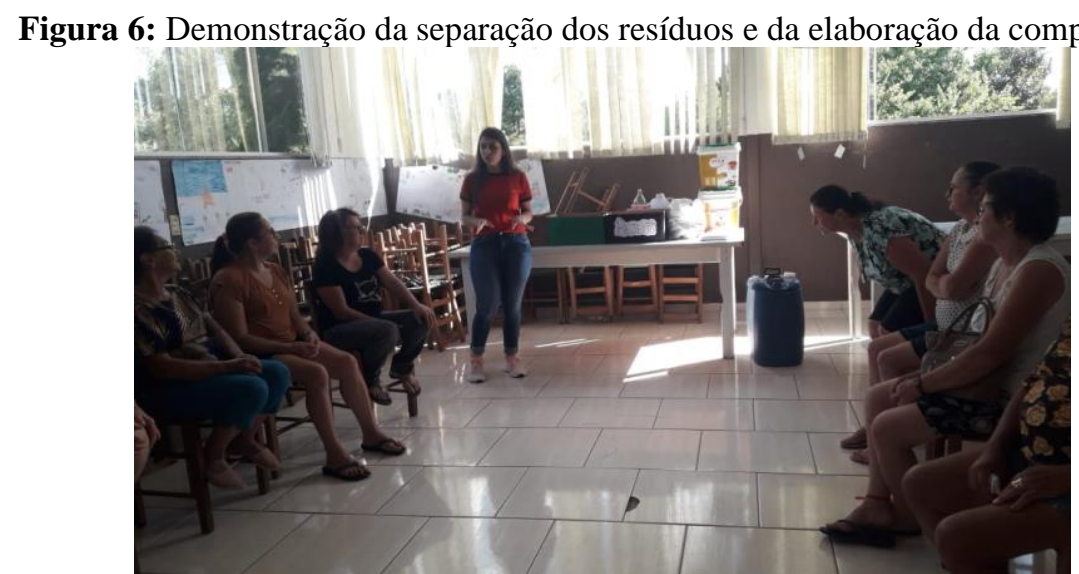

Fonte: a autora (2020)

Em contrapartida, com as mulheres da reserva indígena, realizou-se uma conversa sobre o descarte correto dos resíduos, destacando a não queima deles - ato frequente na comunidade. Em seguida, foram feitos grupos e cada um plantou uma muda de árvore (Figura 7).

Cada grupo ficou responsável por plantar a sua muda onde desejava e determinava mais acessível, pois, posteriormente, terão que dar todos os cuidados necessários para que ela se desenvolva. Assim, contribui-se não somente para o meio ambiente, mas com um lugar que irá se tornar de trocas constantes de experiências, desde o plantio até seu crescimento. 
Figura 7: Muda de árvore plantada pelo grupo do PAIF

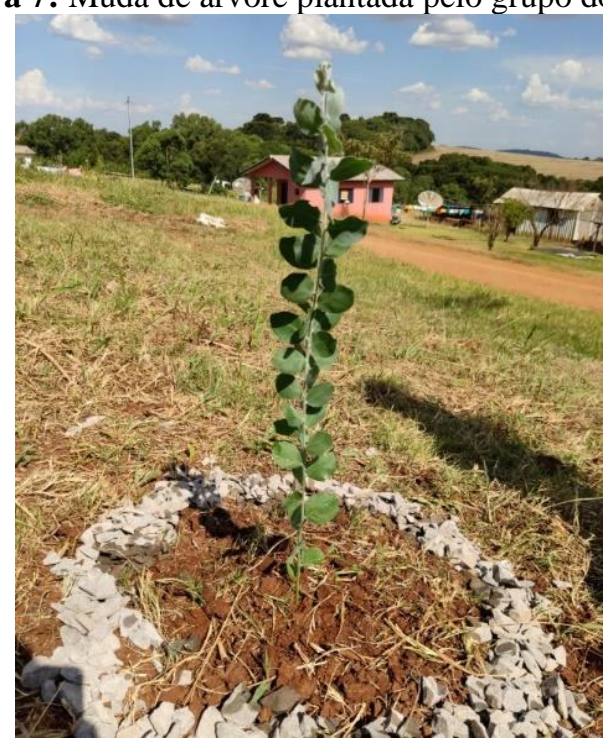

Fonte: autora (2020)

\subsubsection{Englobando outros grupos}

Além dos grupos de usuários (crianças e adolescentes) e do PAIF, pode-se atingir, também, a partir do trabalho desenvolvido, grupos como o de idosos, atendidos pelo CRAS e o grupo do PIM (Primeira Infância Melhor). Com tais grupos, houve conversas a respeito da importância do desenvolvimento de atividades voltadas à educação ambiental.

Com isso, ocorreu um envolvimento não só de um grupo social específico, mas de diferentes grupos com distintas perspectivas da comunidade em geral. Contribuiu-se, dessa forma, para uma visão mais comprometedora com a educação ambiental, ao envolver diferentes grupos de profissionais e instituições, além de desenvolver um diálogo para abordagens inovadoras no campo educacional e ambiental.

\section{Considerações finais}

Ao longo de cada atividade desenvolvida, pode-se observar as diversas mudanças positivas que ocorreram. No âmbito do Centro de Referência e Assistência Social, houve uma mobilização e dedicação de todas as partes envolvidas, e os resultados foram enriquecedores. A partir da interdisciplinaridade, foi possível pensar em diferentes esferas, tanto do ponto de vista emocional, ambiental, social e pedagógico.

A interdisciplinaridade auxiliou e embasou a compreensão dos temas abordados. Os

grupos puderam se expressar e, no momento de cada atividade, foi possível observar os estímulos que foram despertos — que subsidiam uma reeducação voltada para questões socioambientais. 
No ambiente de trabalho, além da maior conscientização de usuários e profissionais, também a partir da pesquisa, os copos descartáveis foram eliminados; eles foram substituídos por canecas e a implementação dos Ecopos (copos ecológicos feitos de papel), para os encontros fornecidos pela assistência social.

A cada mudança de hábito e decisões vamos construindo uma caminhada para novos paradigmas e mudanças, que constroem sujeitos mais críticos. Pode-se constatar como a educação tem a contribuir e o quanto a interdisciplinaridade auxiliou para que o processo fosse mais enriquecedor, para fomentar ideias, criatividade, conscientização, reeducação, socialização e construção de saberes.

As atividades desenvolvidas poderão nortear os educadores ambientais, profissionais da área e professores. É importante um novo olhar para o mundo, ao aplicar metodologias que contribuam para uma educação ambiental efetiva.

\section{Referências}

BRASIL. Ministério do Desenvolvimento Social e Combate à Fome. Tipificação Nacional de Serviços Socioassistenciais. Brasília, DF: MDS, 2013.

CURRIE, K. L. Meio ambiente: Interdisciplinaridade na prática. Campinas: Papirus, 2016.

DOURADO, J.; BELIZÁRIO. Reflexão e práticas em educação ambiental: discutindo e a geração de resíduos. São Paulo: Oficina de Textos, 2012.

FAZENDA, I. Didática e interdisciplinaridade. Campinas: Papirus, 2015.

FAZENDA, I. C. A. Interdisciplinaridade: História, teoria e pesquisa. Campinas: Papirus, 2016.

GUIMARÃES, M. A formação de educadores ambientais. Campinas: Papirus, 2020.

PHILIPPI J. R. A.; PELICIONI, M. C. F. Educação ambiental e sustentabilidade. Barueri: Manole, 2014.

SILVA, C.; PRZYBYSZ, L. C. B. Sistema de Gestão Ambiental. Curitiba: Intersaberes, 2014. 